\title{
Foreword-Special Issue on Metaheuristic Application and Operations Management
}

\author{
Huynh Trung Luong* \\ Department of Industrial and Manufacturing Engineering, School of Engineering and Technology, \\ Asian Institute of Technology, Pathumthani, Thailand
}

* Corresponding Author, E-mail: luong@ait.ac.th

The Asia Pacific Industrial Engineering and Management Systems (APIEMS) Conferences are annual conferences organized by the Asia Pacific Industrial Engineering and Management Society. The core value of APIEMS is associating and exchanging the better industrial engineering education, researches, and exchange information from different countries. Since the first APIEMS conference organized in 1998 in Beijing, China, APIEMS has rapidly emerged as an important forum for exchange of ideas and information about latest developments in the field of industrial engineering and management system among professionals from Asia-Pacific countries.

The 13th Asia Pacific Industrial Engineering and Management Systems Conference (APIEMS2012) was held on December 2-5, 2012 in Phuket City, the capital of the biggest island located in the Andaman Sea of southern Thailand which is also a very famous touristical city. The conference, which covers a wide range of topics in response to the conference theme of "Achieving Sustainability through Effective Resource Management", successfully provided a forum for researchers, university lecturers and engineers to communicate on their latest achievements in the field of industrial engineering and management systems and to seek for future collaboration.

In this special issue of the Industrial Engineering and Management Systems (IEMS), six papers were selected among more than 250 submitted papers to the conference after a usual reviewing process in accordance with the rigorous standards of the journal.

The first paper by Nagasawa et al. considers a coordinated replenishment problem in multi-item inventory control system. A genetic algorithm is developed to help find the solution to the problem. The second paper by Parwananta et al. proposes a two-level genetic algorithm to help find an optimal configuration for a paired single row facility layout problem. The third paper by Song et al. addresses a location and allocation problem of the long term care facilities. An integer programming formulation for the problem is developed and numerical experiments are conducted to illustrate the applicability of the developed model. In the fourth paper, Ai et al. proposes a new solution methodology for the team orienteering problem by use of particle swarm optimization technique. The performance of the proposed algorithm is then tested with various benchmark problems. In the fifth paper, Masruroh and Mulyani develop a mathematical model for revenue management with overbooking and costly price adjustment in hotel industries. Lagrangian relaxation technique is then employed for solution purpose. Last but not least, Lumsakul and Luong study a composite revenue sharingquantity flexibility contract. The ability of the proposed composite contract to help coordinate the supply chain as well as to help allocate profit among supply chain members is illustrated through various numerical experiments.

As guest editor for this special issue, I would like to thank the authors for their contributions and the reviewers for their time that helped improve the quality of this issue. I would like to specially thank the editor-in-chief of IEMS, Prof. Mitsuo Gen, for giving me the opportunity to publish selected papers as a special issue of the journal. I would also like to thank the managing editor, Prof. Chi-Hyuck Jun, for guiding me through the editorial process. It was a pleasure to take part in this special issue for IEMS. 